\title{
MELAN-A AS A USEFUL DIAGNOSTIC IMMUNOHISTOCHEMICAL STAIN FOR THE DIAGNOSIS OF PRIMARY SINONASAL MELANOMAS
}

\author{
Matthew L. Snyder, MD, Augusto F. G. Paulino, MD \\ Department of Pathology, University of Michigan Hospitals, 1500 East Medical Center Drive, Room 2 G332, \\ Ann Arbor, MI 48109. E-mail: paulino@umich.edu
}

Accepted 8 June 2001

\begin{abstract}
Background. Sinonasal melanomas are rare neoplasms whose diagnosis may require confirmatory immunohistochemical stains. S-100 protein and HMB- 45 , the stains most commonly used, have varying sensitivities and specificities. Melan-A, a more recent melanoma-specific marker, may prove helpful when S-100 protein and HMB- 45 stains are negative or equivocal.

Methods. Seven cases of sinonasal melanoma were assessed for reactivity with Melan-A, S-100 protein and HMB-45.

Results. The study group consisted of two women and five men ages 40 to 83 . Six of the neoplasms were strongly positive for $\mathrm{S}-100$ protein. One case was negative for S-100 protein and HMB-45 but positive for Melan-A. HMB-45 staining varied between diffusely positive (three cases), focally positive (two cases), and negative (two cases). All cases were positive for Melan-A either diffusely (four cases) or focally (three cases).

Conclusion. Because Melan-A can be positive in cases that are $\mathrm{S}-100$ protein or HMB- 45 negative, it is a useful component in the immunohistochemical panel for the diagnosis of sinonasal melanomas. () 2002 John Wiley \& Sons, Inc. Head Neck 24: 52-55, 2002.
\end{abstract}

Keywords: sinonasal melanoma; immunohistochemistry

Correspondence to: A. F. G. Paulino

Presented at the 5th International Conference on Head and Neck Cancer, San Francisco, California, August 1, 2000.

(C) 2002 John Wiley \& Sons, Inc.

DOI 10.1002/hed.10007
Primary mucosal malignant melanomas are rare neoplasms accounting for only $0.4 \%$ of all malignant melanomas and for $10 \%$ of melanomas in the head and neck region. ${ }^{1,2}$ Overall, melanomas account for less than $7 \%$ of all sinonasal neoplasms. ${ }^{2}$

Sinonasal melanomas usually are seen as polypoid growths in the nasal cavity, antrum, ethmoid, or frontal sinuses. ${ }^{3}$ They are believed to arise from stromal and mucosal melanocytes of the respiratory tract. ${ }^{4}$ Although the histologic appearance of sinonasal melanomas often can be easily recognized, some cases may pose a diagnostic challenge because of the lack of pigmentation, marked nuclear pleomorphism, a predominant spindle cell appearance, extensive necrosis, or because of a very limited biopsy. As such, immunohistochemical confirmation of the morphologic impression of melanoma is often undertaken. The immunohistochemical profile of the sinonasal melanomas resembles that of their cutaneous counterparts, staining positively for S-100 protein, HMB-45, and vimentin. ${ }^{5}$ More recently, Melan-A has been added to this list and its usefulness as a diagnostic aid in sinonasal melanomas is evaluated here. 


\section{MATERIALS AND METHODS}

Seven cases of primary sinonasal melanoma were retrieved from the surgical pathology files of the University of Michigan Hospitals from the years 1992 to 2000 . Patients with a prior cutaneous or ocular melanoma were excluded. Paraffin-embedded, $\mathrm{H}$ \& $\mathrm{E}$-stained histologic sections of each tumor were reviewed to confirm the diagnosis of melanoma. The morphologic features (histologic appearance, melanin pigmentation, necrosis, mitotic activity) of each of the tumors was assessed on $\mathrm{H} \& \mathrm{E}$-stained sections.

Five micron-thick sections were cut onto coated slides, deparaffinized in xylene, and rehydrated in descending grades of ethanol $(100 \%-70 \%)$. Endogenous peroxidase and nonspecific binding were blocked before the addition of the primary antibody. All cases were stained for S-100 protein (1:500 dilution), HMB-45 (1:10 dilution), and Melan-A (1:12.5 dilution) using the manufacturer's recommendations (DAKO, Carpinteria, CA) on an automated Ventana stainer. The appropriate secondary antibodies were detected using the avidin-biotin peroxidase method. Sections from cutaneous melanoma served as positive controls and were stained in parallel.

To be considered positive for S-100 protein, the staining had to be nuclear; whereas staining for HMB-45 and Melan-A was cytoplasmic and membranous, respectively. All cases were reviewed independently by the two authors.

\section{RESULTS}

Clinical and pathologic features are summarized in Table 1. There were two women and five men, ages 40 to 83 (mean age, 65). Six of the patients were initially seen with polypoid masses measuring 1.0 to $4.2 \mathrm{~cm}$ (Fig. 1) and symptoms of nasal congestion, facial tenderness, and epistaxis. The remaining patient was initially seen with epistaxis but had a flat, ulcerated lesion. All patients were treated with resection followed by radiation therapy. For two patients, the resection was only palliative. Four patients, three of whom had local recurrence, had metastatic disease in either the cervical lymph nodes or in distant sites such as the cecum and sacrum. Three of the patients died from their disease 10, 24, and 56 months after initial presentation. One patient is currently alive but has documented metastatic disease. Two patients are disease-free with follow-up intervals of 85 and 26 months, respectively. The most recent patient is only 2 months out from his primary resection but has no radiographic evidence of metastasis.

The histologic findings of these neoplasms were varied, but most of the tumors displayed an epithelioid appearance (Fig. 2). Four cases had melanin formation. No perineural invasion was noted in any of the cases. There were up to seven mitotic figures per square millimeter, with the worst outcomes in two cases with higher mitotic rates and which also exhibited extensive necrosis. Six of the seven cases stained positively with S100 protein. HMB-45 staining was diffusely pos-

Table 1. Clinical, histologic, and immunohistochemical features of patients with primary sinonasal melanoma.

\begin{tabular}{|c|c|c|c|c|c|c|c|c|c|c|}
\hline Age/gender & Symptoms & Pigment & Necrosis & Mitosis & S-100 & HMB-45 & Melan-A & Treatment & Follow-up* & Status \\
\hline $40 / \mathrm{M}$ & Congestion & N & $\mathrm{N}$ & 1 & Y & Y & $\mathrm{F}$ & $\begin{array}{l}\text { Surgery } \\
\text { Radiation }\end{array}$ & 85 & NOD \\
\hline $74 / \mathrm{M}$ & $\begin{array}{l}\text { Congestion, } \\
\text { mental status } \\
\text { changes }\end{array}$ & Y & Y & 7 & Y & $\mathrm{F}$ & $\mathrm{F}$ & $\begin{array}{l}\text { Surgery } \\
\text { Radiation }\end{array}$ & 10 & DOD \\
\hline $83 / F$ & Congestion & Y & $N$ & $<1$ & Y & Y & Y & $\begin{array}{l}\text { Surgery } \\
\text { Radiation }\end{array}$ & 26 & NOD \\
\hline $57 / \mathrm{M}$ & $\begin{array}{l}\text { Obstruction, } \\
\text { tenderness }\end{array}$ & $\mathrm{N}$ & $N$ & $<1$ & Y & $\mathrm{N}$ & Y & $\begin{array}{l}\text { Surgery } \\
\text { Radiation }\end{array}$ & 56 & DOD \\
\hline $76 / \mathrm{M}$ & $\begin{array}{l}\text { Congestion, } \\
\text { epistaxis }\end{array}$ & Y & $N$ & 3 & Y & Y & Y & $\begin{array}{l}\text { Surgery } \\
\text { Radiation }\end{array}$ & 24 & DOD \\
\hline $47 / F$ & Congestion & $N$ & Y & 3 & Y & $\mathrm{F}$ & Y & $\begin{array}{l}\text { Surgery } \\
\text { Radiation }\end{array}$ & 10 & AWD \\
\hline $75 / \mathrm{M}$ & Epistaxis & Y & $N$ & $<1$ & $\mathrm{~N}$ & $\mathrm{~N}$ & Y & $\begin{array}{l}\text { Surgery } \\
\text { Radiation }\end{array}$ & 2 & NOD \\
\hline
\end{tabular}

*Number of months after initial presentation.

Abbreviations: $A W D$, alive with disease; $D O D$, dead of disease; $F$, focal; $N$, no; NOD, no evidence of disease; $Y$, yes. 


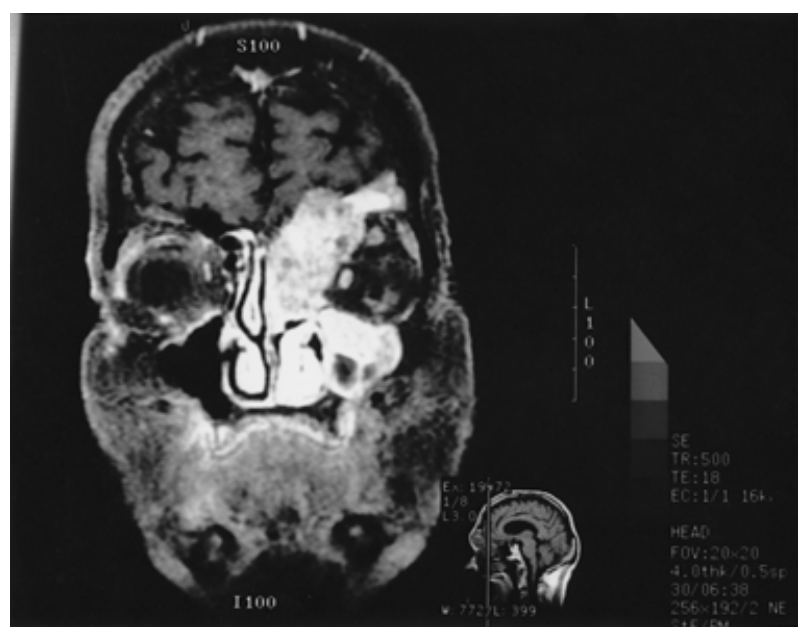

FIGURE 1. MRI showing extensive malignant melanoma involving the nasal cavity.

itive in three cases, faint in two, but negative in two. All of the cases stained with Melan-A, either diffusely in four cases or focally in the remaining three cases (Fig. 3).

Because one of the lesions stained only with Melan-A, an additional immunohistochemical stain, tyrosinase, was used in confirming the histologic impression of this neoplasm. This neoplasm displayed strong cytoplasmic staining with tyrosinase, confirming the histologic impression and further supporting the positive staining with Melan-A. Tyrosinase is a specific cytoplasmic enzyme found in melanocytic cells. Its usefulness and specificity as an immunohistochemical stain for the diagnosis of melanoma has been previously assessed. ${ }^{6}$

\section{DISCUSSION}

Sinonasal melanomas typically occur in elderly patients. There is a slight male predominance.

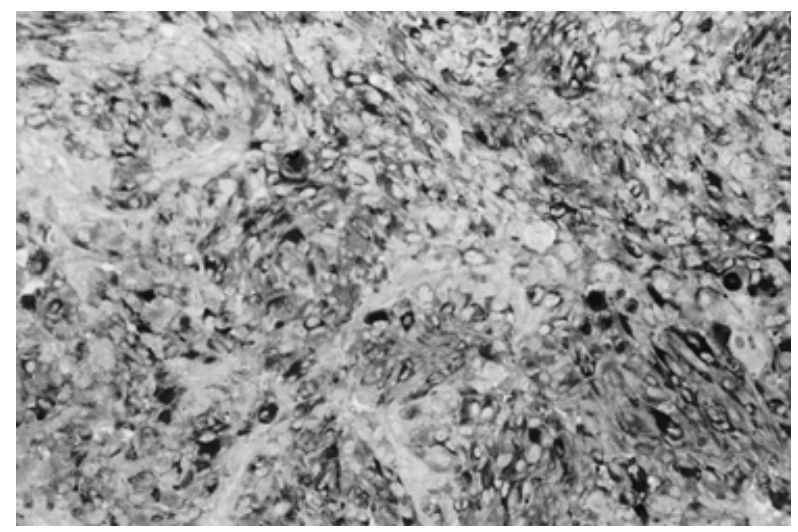

FIGURE 3. Cytoplasmic staining of melanoma with Melan-A.

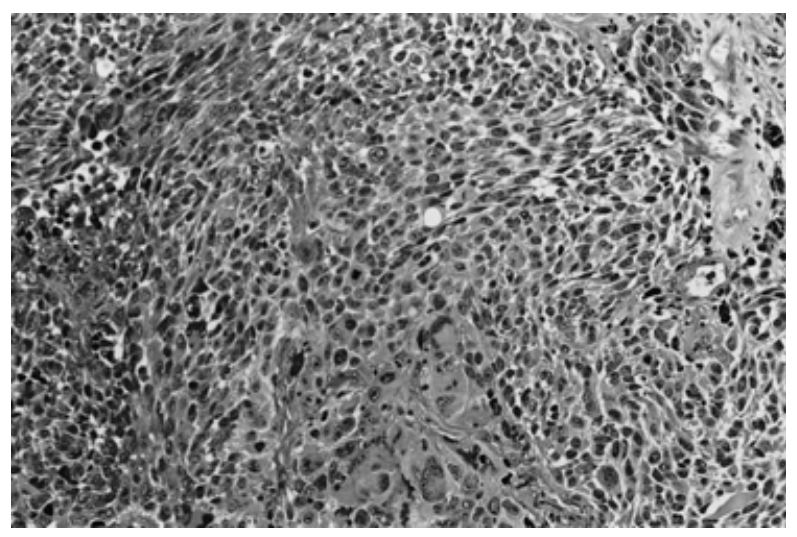

FIGURE 2. Microscopic appearance of melanoma with pleomorphic epithelioid cells.

Most are polypoid masses associated with nasal obstruction and epistaxis. ${ }^{3,7}$ The most common locations are the nasal septum, lateral wall, inferior and middle turbinate, and vestibule, but these tumors may extend into the paranasal sinuses. ${ }^{3}$ A significant number of mucosal melanomas are amelanotic, although melanin may be demonstrated microscopically in up to $70 \%$ of cases. ${ }^{8}$ Melanotic content accounts for high signal intensity of sinonasal melanomas on T1-weighted images. ${ }^{9}$

The histologic diagnosis of melanoma is often straightforward. The tumors may be epithelioid, plasmacytoid, spindle, pleomorphic, or undifferentiated small round cell types. Because of this cytologic variation, compounded by very limited biopsy material obscured by necrosis, the pathologic interpretation can be difficult. For this reason, immunohistochemical stains are commonly used to confirm an impression of melanoma. The stains most commonly used are S-100 protein and HMB- 45 .

$\mathrm{S}-100$ protein is a dimeric calcium-binding protein. It is composed of different combinations of alpha and beta subunits located in the nucleus and cytoplasm of glial and Schwann cells, melanocytes, chondrocytes, adipocytes, and myoepithelial cells or from tumors derived from any of these cell types. Thus, although S-100 protein may be a sensitive marker, it is quite nonspecific.

HMB-45, a monoclonal antibody derived from an extract of malignant melanoma, identifies an oncofetal glycoconjugate associated with immature melanosomes. Although it is expressed by melanomas, other neoplasms such as angiomyolipomas, other components of the tuberous sclerosis complex, and occasionally carcinomas may also express HMB- 45 . 
More recently, Melan-A has been added to the pathologist's armamentarium in diagnosing melanomas, and its usefulness in a panel of immunohistochemical stains for the accurate diagnosis of primary and metastatic cutaneous melanomas has been established. ${ }^{6,10}$ In addition, it has been found to be highly specific in distinguishing metastatic melanoma from other lesions such as poorly differentiated carcinomas, sarcomas of varying histogenesis, Leydig tumors, high-grade lymphomas, and plasmablastic/anaplastic myelomas. ${ }^{10}$ The Melan-A gene, cloned by Coulie et $\mathrm{al}^{11}$ from a human melanoma cell line, encodes a melanoma-specific antigen recognized by autologous cytotoxic lymphocytes. By analyzing the antigenic targets of tumor-infiltrating lymphocytes from a melanoma specimen, Kawakami et $\mathrm{al}^{12}$ independently cloned the same gene, designated MART-1. The function of this Melan-A/ MART-1 antigen is not yet known. Melan-A/ MART-1 RNA is not detected in normal tissues except for the retina.

Histologic prognostic factors in mucosal melanomas have lagged behind their cutaneous counterparts. Tumor stage at presentation seems to be the only prognostic parameter of significance. ${ }^{13}$ However, the Clark system cannot be used for staging because of the difference in the squamous mucosa of the skin and the columnar mucosa of the respiratory tract. Because the nasal mucosa closely approximates bone, even thin malignant melanomas may invade the underlying bone. Head and neck melanomas, even their cutaneous counterparts, are more aggressive than melanomas elsewhere. In the head and neck mucosa, 5and 10 -year survival is $17 \%$ and $5 \%$, respectively. ${ }^{1}$ Despite advances in imaging and treatment, the mean survival of patients with sinonasal melanomas has not substantially changed. ${ }^{14}$ The mean survival is between 2.5 and 3.5 years. ${ }^{15}$

The differential diagnoses of sinonasal melanomas include undifferentiated carcinomas, olfactory neuroblastomas, and paragangliomas. Olfactory neuroblastomas typically display a fine fibrillary background and may stain with S-100 protein and occasionally with HMB- $45 .{ }^{16}$ However, most will also stain with microtubule-associated protein MAP-2 and cytokeratin and epithelial membrane antigen. Undifferentiated carcinomas will stain for cytokeratin but not for S-100 protein or HMB-45. Paragangliomas have a characteristic nested (Zellballen) growth pattern on light microscopy with only the sustentacular cells staining for S-100 protein.
Our data demonstrate the histologic diversity of sinonasal melanomas and their variable reactivity to immunohistochemical stains for S-100 protein and HMB-45. For this reason, Melan-A seems to be a useful immunohistochemical stain for the diagnosis of sinonasal melanomas.

\section{REFERENCES}

1. Chiu NT, Weinstock MA. Melanoma of the oronasal mucosas. Population based analysis of occurrence and mortality. Arch Otolaryngol Head Neck Surg 1996;122: 9851003.

2. Conley JJ. Melanoma of the head and neck. 1st ed. New York: George Thieme Verlag; 1990. p 154-165.

3. Holdcraft J, Gallagher JC. Malignant melanomas of the nasal and paranasal sinus mucosa. Ann Otol Rhinol Laryngol 1969;78:5-20.

4. Huntrakoon M, Nyong'o AO. Primary malignant melanoma of the nasal cavity. Report of two cases with emphasis on histogenesis. Surg Pathol 1989;2:59-66.

5. Fraquemont DW, Mills SE. Sinonasal malignant melanomas. A clinicopathologic and immunohistochemical study of 14 cases. Am J Clin Pathol 1991;96:689-697.

6. Busam KJ, Jungbluth AA. Melan-A, a new melanocytic differentiation marker. Adv Anat Pathol 1999;6(1): 12-18.

7. Matias C, Corde J, Soares J. Primary malignant melanomas of the nasal cavity. J Surg Oncol 1988;39:29-35.

8. Mills SE, Fechner RE. The nose, paranasal sinuses and nasopharynx. In: Sternberg S, editor. Diagnostic surgical pathology, 3rd ed. Philadelphia: Lippincott Williams \& Wilkins; 1999. p 885-924.

9. Yousem DM, Li C, Montone KT, et al. Primary malignant melanoma of the sinonasal cavity: MR imaging evaluation. Radiographics 1996;16:1101-1110.

10. Kaufmann O, Koch S, Burghardt J, Audring H, et al. Tyrosinase, Melan-A, and KBA62 as markers for the immunohistochemical identification of metastatic amelanotic melanomas on paraffin sections. Mod Pathol 1998; 11(8): 740-746.

11. Coulie PG, Brichard V, Van Pel A, et al. A new gene coding for a differentiating antigen recognized by autologous cytolytic T lymphocytes on HLA-A2 melanomas. J Exp Med 1994;180:35-42.

12. Kawakami Y, Eliyahu S, Delgado CH, et al. Cloning of the gene coding for a shared human melanoma antigen recognized by autologous T cells infiltrating into tumor. Proc Natl Acad Sci USA 1994;91:3515-3519.

13. Regauer S, Ott A, Berghold A, Beham A. CD44 expression in sinonasal melanomas: is loss of isoform expression associated with advanced tumour stage? J Pathol 1999; 187:184-190.

14. Brandwein MS, Rothstein A, Lawson W, et al. Sinonasal melanoma: a clinicopathologic study of 25 cases with literature meta-analysis. Arch Otolaryngol Head Neck Surg 1997;123:290-296.

15. Bender L, Rowley S. Sinonasal melanoma: an unusual case of proptosis. Eye 1999;13:682-683.

16. Wick MR, Stanley SJ, Swanson PE. Immunohistochemical diagnosis of sinonasal melanoma, carcinoma, and neuroblastoma with monoclonal antibodies HMB- 45 and antisynaptophysin. Arch Path Lab Med 1988;112:616-620. 